\title{
Manic Episode Associated with Mega Cisterna Magna
}

\author{
Tayfun Turan ${ }^{凶}$, Aslı Beșirli, Akif Asdemir, Saliha Özsoy and Ertuğrul Eşel \\ Department of Psychiatry, Erciyes University Medical School, Kayseri, Turkey
}

\begin{abstract}
Mega cisterna magna is a part of "Dandy-Walker Complex" and it is characterized by the enlargement of the cisterna magna, morphologically intact vermis and cerebellar hemispheres. We report a case of manic attack in a 23-year-old man with mega cisterna magna. The patient was treated with quetiapine $1,000 \mathrm{mg} /$ day and sodium valproate $1,500 \mathrm{mg} /$ day and the symptoms were ameliorated within $2.5 \mathrm{months}$. In this case, mega cisterna magna and manic symptoms may be found together coincidentally or any cerebellar dysfunction due to mega cisterna magna may cause or contribute to the appearance of affective symptoms. To our knowledge, this is the first case reporting manic attack with psychotic symptoms associated with mega cisterna magna. This report suggests that any lesion in the cerebellum might contribute to the occurrences of some affective and psychotic symptoms seen in bipolar disorder.

Psychiatry Investig 2010;7:305-307
\end{abstract}

Key Words Bipolar disorder, Magnetic resonance imaging, Cerebellum, Mega cisterna magna.

\section{INTRODUCTION}

The cerebellum plays an important role in coordination and motor functions. ${ }^{1}$ Besides its involvement in motor and vestibulo-ocular regulation, it is considered to be involved in modulation of mood. ${ }^{2}$ Cerebellar structures, especially the vermis, are considered to be associated with the pathophysiology of psychiatric disorders such as schizophrenia. ${ }^{3}$

Cystic or cystlike malformations of the posterior fossa include the Dandy-Walker malformation, vermian-cerebellar hypoplasia, mega cisterna magna and arachnoid cyst. Mega cisterna magna is a developmental variation of the posterior fossa characterized by the enlargement of the cisterna magna, morphologically intact vermis and cerebellar hemispheres. ${ }^{4}$

Bipolar disorder is a chronic and life-long condition which is characterized by shifts in energy level, mood state, behaviours ${ }^{5}$ and psychotic symptoms such as hallucinations and delusions. ${ }^{6}$ The cerebellum is suggested to interfere in the pathophysiology of bipolar disorder. ${ }^{7}$ It has connections via thalamus to several brain regions such as dorsolateral prefrontal cortex, medial frontal cortex, anterior cingulate and the posterior hypotha-

Received: May 26, 2010 Revised: August 18, 2010

Accepted: September 7, 2010 Available online: November 9, 2010

$\triangle$ Correspondence: Tayfun Turan, MD

Department of Psychiatry, Erciyes University Medical School, 38039 Kayseri, Turkey

Tel: +90-352-4372583, Fax: +90-352-4372583

E-mail: tayfunturan@hotmail.com

(c) This is an Open Access article distributed under the terms of the Creative Commons Attribution Non-Commercial License (http://creativecommons.org/licenses/by$\mathrm{nc} / 3.0$ ) which permits unrestricted non-commercial use, distribution, and reproduction in any medium, provided the original work is properly cited. lamus which are all associated with behaviour and cognition. ${ }^{8}$ The cerebellum could also be involved in emotions and affective disorders throughout its connections to limbic system. ${ }^{9}$

In a clinical study "The cerebellar cognitive affective syndrome" was described to be characterized by executive dysfunctions, behavioral disinhibition and emotion dysregulation in patients with posterior and vermal lesions. ${ }^{10}$ Moreover, there are cases reporting psychotic episodes associated with DandyWalker variant or mega-cisterna magna in the literature. ${ }^{11,12}$

We report a case of manic attack in a 23-year-old man with mega cisterna magna. To our knowledge, this is the first case to report manic attack with psychotic symptoms associated with mega cisterna magna.

\section{CASE}

A 23-year-old man with a 2-week history of manic symptoms presented with inappropriate and euphoric affect, flight of ideas, inflated self-esteem, increased immersion in projects, excessive shopping, increased energy, decreased need for sleep, excessive talking, irritability, aggressive behaviours and psychotic symptoms such as auditory hallucinations, delusions of grandiosity and reference. He expressed odd beliefs that he could read people's mind. A few days before admission to hospital he pretended to be God and Prophet. He experienced the first episode and partially displayed insight into his condition. Premorbid educational and social adjustment were reported normal. There was no history of alcohol or substance misuse. A family history of depression in his father was reported. 

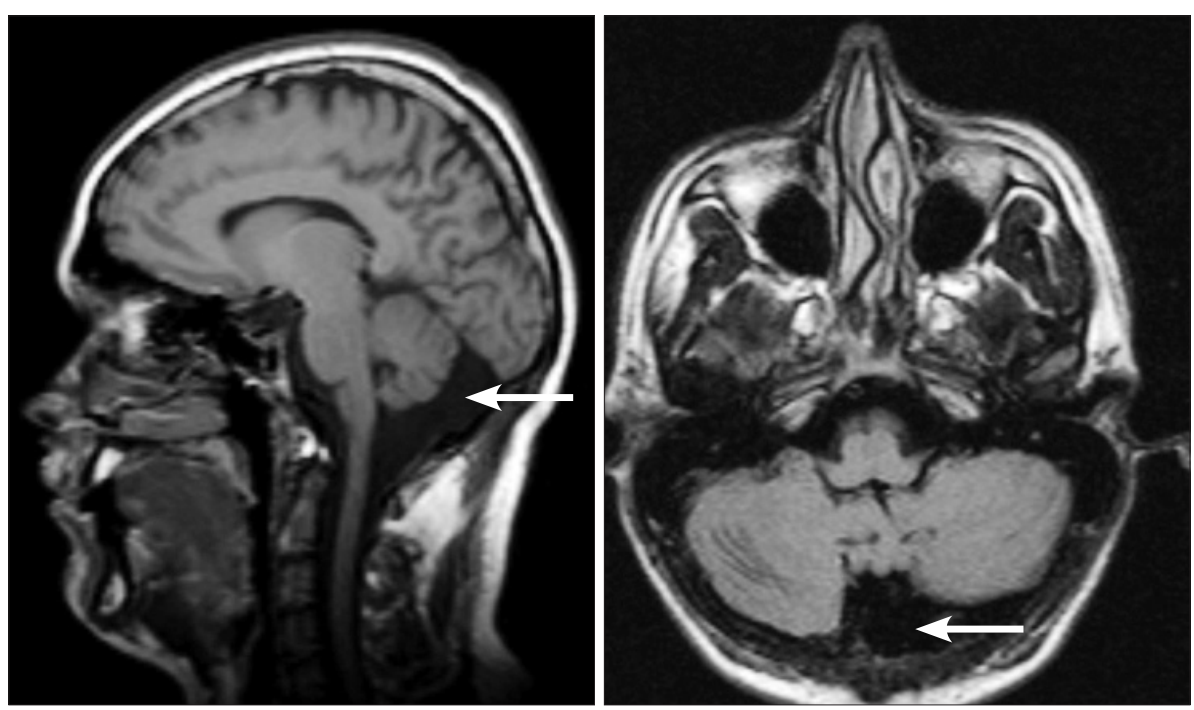

Figure 1. Magnetic resonance imaging midsagital and transverse scans: megacisterna magna.
Neurological examination and electroencephalography were normal. Cranial Magnetic Resonance Imaging (MRI) scan disclosed "mega cisterna magna" (Figure 1). The full scale IQ was 86. Both performance and verbal IQ were 86 . The Young Mania Rating Scale (YMRS) ${ }^{13}$ was performed before and after the treatment.

Olanzapine treatment was started at a dosage of $20 \mathrm{mg} /$ day on the first day of the admission to hospital and increased to 30 $\mathrm{mg}$ /day on the 13th day. But no significant improvement was observed. For this reason, olanzapine treatment was gradually decreased and stopped. Then, haloperidol $20 \mathrm{mg} /$ day and biperiden $6 \mathrm{mg}$ /day were started. After haloperidol dose was gradually increased to $40 \mathrm{mg} /$ day, extrapyramidal symptoms such as dystonia occurred. However, a significant remission in hallucinations was observed. Because of extrapyramidal symptoms, haloperidol was stopped and quetiapine treatment was started and gradually increased to $1,000 \mathrm{mg} /$ day. Moreover, a mood stabilizer sodium valproate was added at a dosage of 500 $\mathrm{mg} /$ day to the treatment and its dosage was increased to 1,500 $\mathrm{mg} /$ day due to blood levels (Valproic acid blood level: $92.9 \mu \mathrm{g} / \mathrm{mL}$ ).

A significant improvement in YMRS score was observed after the treatment. This score decreased by $100 \%$ (from 51 to 0 ) within 2.5 months.

On the follow-up period his affect changed into euthymic state, and hallucinations and delusions disappeared. He was discharged with full remission 2.5 months after the admission and he is still in remission of manic symptoms with the treatment of valproic acid and quetiapine.

\section{DISCUSSION}

In this case report, mega cisterna magna and symptoms of manic attack may be found coincidentally together or any cerebellar dysfunction due to mega cisterna magna may cause or contribute to the appearance of affective symptoms. Unlike schizophrenia, there are few studies stressing the role of cerebellum in bipolar disorder.

A model was suggested to explain "misconnections" between cortical regions and the cerebellum mediated through the thalamus in schizophrenia (the cortico-cerebellar-thalamic-cortical circuit). ${ }^{14}$ Psychotic symptoms such as hallucinations may occur in case of an abnormality in this circuit. ${ }^{15}$ It is also considered that cerebellar feedback pathways through the thalamus to the cerebral cortex may play a role in peduncular hallucinations. ${ }^{16}$ In addition, brain imaging studies have found negative correlations between cerebellar grey matter volume reduction and hallucinations in schizophrenic patients. ${ }^{15}$ Similarly, it is reported that there is a dysregulation of cortico-subcortical and cerebellar regions in bipolar patients, ${ }^{17}$ which may contribute to the occurrence of symptoms. Moreover, in a study it was found that there was a significant correlation between delusions and activation of cerebellum. ${ }^{18}$ In this case, mega cisterna magna might contribute to the activation of cerebellum. In the light of these findings, in our case we can suggest that at least in some cases of bipolar disorder, cerebellar dysfunction may interfere in the occurrence of affective and psychotic symptoms such as hallucinations and delusions. In addition, the reason of alleviation of symptoms only with high doses of antipsychotics may be due to the involvement of cerebellum in this case.

Cerebellar vermal neurons may play a role in the modulation of mood. ${ }^{19}$ Also, vermal lesions are associated with behavioural and affective changes. ${ }^{20}$ However, in this case MRI scan did not demonstrate any lesion in vermis.

In conclusion, this report suggests that any dysfunction in cerebellum might contribute to the occurrence of some affective and psychotic symptoms seen in bipolar disorder. 


\section{REFERENCES}

1. Schmahmann JD. An emerging concept. The cerebellar contribution to higher function. Arch Neurol 1991;48:1178-1187.

2. Brambilla P, Harenski K, Nicoletti M, Mallinger AG, Frank E, Kupfer DJ, et al. MRI study of posterior fossa structures and brain ventricles in bipolar patients. J Psychiatr Res 2001;35:313-322.

3. Ichimiya T, Okubo Y, Suhara T, Sudo Y. Reduced volume of the cerebellar vermis in neuroleptic-naive schizophrenia. Biol Psychiatry 2001;49: 20-27.

4. Kollias SS, Ball WS Jr, Prenger EC. Cystic malformations of the posterior fossa: differential diagnosis clarified through embryologic analysis. Radiographics 1993;13:1211-1231.

5. Baldaçara L, Borgio JG, Lacerda AL, Jackowski AP. Cerebellum and psychiatric disorders. Rev Bras Psiquiatr 2008;30:281-289.

6. Goes FS, Sadler B, Toolan J, Zamoiski RD, Mondimore FM, Mackinnon DF, et al.; Bipolar Disorder Phenome Group, Raymond Depaulo J Jr, Potash JB. Psychotic features in bipolar and unipolar depression. Bipolar Disord 2007;9:901-906.

7. Strakowski SM, Adler CM, DelBello MP. Volumetric MRI studies of mood disorders: do they distinguish unipolar and bipolar disorder? Bipolar Disord 2002;4:80-88.

8. Rapoport M, van Reekum R, Mayberg H. The role of the cerebellum in cognition and behavior: a selective review. J Neuropsychiatry Clin Neurosci 2000;12:193-198.

9. Schutter DJ, van Honk J. The cerebellum on the rise in human emotion. Cerebellum 2005;4:290-294

10. Schmahmann JD, Sherman JC. The cerebellar cognitive affective syndrome. Brain 1998;121:561-579.

11. Ferentinos PP, Kontaxakis VP, Havaki-Kontaxaki BJ, Paplos KG, Pappa
DA, Soldatos CR. Refractory psychosis and prominent cognitive deficits in a patient with mega-cisterna magna. Prog Neuropsychopharmacol Biol Psychiatry 2007;31:561-563.

12. Langarica M, Peralta V. [Psychosis associated to megacisterna magna.] An Sist Sanit Navar 2005;28:119-121.

13. Young RC, Biggs JT, Ziegler VE, Meyer DA. A rating scale for mania: reliability, validity and sensitivity. Br J Psychiatry 1978;133:429-435.

14. Andreasen NC. A unitary model of schizophrenia: Bleuler's "fragmented phrene" as schizencephaly. Arch Gen Psychiatry 1999;56:781-787.

15. Neckelmann G, Specht K, Lund A, Ersland L, Smievoll AI, Neckelmann $\mathrm{D}$, et al. Mr morphometry analysis of grey matter volume reduction in schizophrenia: association with hallucinations. Int J Neurosci 2006; 116:9-23.

16. Manford M, Andermann F. Complex visual hallucinations. Clinical and neurobiological insights. Brain 1998;121:1819-1840.

17. Mahon K, Wu J, Malhotra AK, Burdick KE, DeRosse P, Ardekani BA, et al. A voxel-based diffusion tensor imaging study of white matter in bipolar disorder. Neuropsychopharmacology 2009;34:1590-1600.

18. Whalley HC, Gountouna VE, Hall J, McIntosh A, Whyte MC, Simonotto $\mathrm{E}$, et al. Correlations between fMRI activation and individual psychotic symptoms in un-medicated subjects at high genetic risk of schizophrenia. BMC Psychiatry 2007;7:61.

19. Mills NP, Delbello MP, Adler CM, Strakowski SM. MRI analysis of cerebellar vermal abnormalities in bipolar disorder. Am J Psychiatry 2005; 162:1530-1532.

20. Richter S, Schoch B, Kaiser O, Groetschel H, Dimitrova A, Hein-Kropp $\mathrm{C}$, et al. Behavioral and affective changes in children and adolescents with chronic cerebellar lesions. Neurosci Lett 2005;381:102-107. 